\title{
Estudo fenológico de espécies arbóreas nativas em uma unidade de conservação de caatinga no Estado do Rio Grande do Norte, Brasil
}

\author{
Diego Nathan do Nascimento Souza ${ }^{1 *}$ \\ Ramiro Gustavo Valera Camacho ${ }^{2}$ \\ José Iranildo Miranda de Melo ${ }^{3}$ \\ Lamarck do Nascimento Galdino da Rocha ${ }^{4}$ \\ Noelia Ferreira da Silva ${ }^{1}$ \\ ${ }^{1}$ Departamento de Biologia, Universidade Federal Rural de Pernambuco \\ Rua Dom Manoel de Medeiros, s/n, CEP: 52171-900, Recife - PE, Brasil \\ ${ }^{2}$ Departamento de Biologia, Faculdade de Ciências Exatas e Naturais \\ Universidade do Estado do Rio Grande do Norte, Mossoró - RN, Brasil \\ ${ }^{3}$ Departamento de Biologia, Universidade Estadual da Paraíba, Campina Grande - PB, Brasil \\ ${ }^{4}$ Universidade Estadual de Feira de Santana, Feira de Santana - BA, Brasil \\ * Autor para correspondência \\ diego_nathan@yahoo.com.br
}

Submetido em $28 / 11 / 2012$

Aceito para publicação em 06/02/2014

\section{Resumo}

A fenologia observa o desenvolvimento vegetativo e reprodutivo das plantas e a interferência que fatores bióticos e abióticos realizam em cada evento fenológico. Entretanto, estudos fenológicos são ainda incipientes em florestas tropicais secas, especialmente no Semiárido brasileiro. Assim, objetivou-se estudar a fenologia de seis espécies lenhosas da caatinga (Dipteryx odorata, Cordia oncocalyx, Poincianella pyramidalis, Manihot pseudoglaziovii, Handroanthus heptaphyllus e Pseudobombax cf. marginatum), além da relação entre fenofases e variáveis ambientais. As fenofases foram observadas em viagens quinzenais à Floresta Nacional de Açu, Nordeste do Brasil. O brotamento foliar ocorreu no início da estação chuvosa e queda foliar no início da seca. Verificou-se que apenas Dipteryx odorata não floresceu. As outras espécies floresceram em meados da estação chuvosa ou no final desta. A frutificação ocorreu geralmente em meados do período chuvoso e no início do seco. A precipitação foi o fator que mais influenciou as fenofases. No entanto, outras variáveis também apresentaram uma correlação significativa principalmente com brotamento e queda foliar. Os dados fenológicos detectados para essas espécies foram similares aos observados em outras áreas de caatinga, sugerindo que as plantas lenhosas desse ecossistema possuem uma tendência de suas fenofases, com poucas modificações ao longo de um gradiente espacial e temporal.

Palavras-chave: Fenofases; FLONA/Açu; Floração; Frutificação; Semiárido

\section{Abstract}

Phenological study of native tree species in a protected area of caatinga in Rio Grande do Norte State, Brazil. Phenology takes into consideration the vegetative and reproductive development of plants under 
the influence of biotic and abiotic factors at each stage. However, phenological studies are still incipient for dry tropical forests, especially for the Brazilian semiarid area. Hence, the objective of this study was to follow the phenology of six woody species belonging to the caatinga ecosystem (Dipteryx odorata, Cordia oncocalyx, Poincianella pyramidalis, Manihot pseudoglaziovii, Handroanthus heptaphyllus and Pseudobombax cf. marginatum), and also to determine the relationship between environmental variables and phenophases. The phenophases were observed during field trips to the National Forest of Açu, Northeast Brazil, made twice a month. All species showed peak leaf budding at the beginning of the rainy season and lost their leaves early in the dry season. It was observed that Dipteryx odorata did not flower. The other species flowered in the middle or end of the rainy season. Fruiting generally occurred between the middle of the rainy season and beginning of dry season for five species. Precipitation was the factor that most affected the phenophases. However, the other variables also exhibited a significant correlation with budding and leaf fall. Phenological databases collected for the species of interest were in agreement with those of other areas where caatinga prevails, suggesting that woody species of such ecosystem have a specific phenological trend, showing small changes over space and time.

Key words: FLONA/Açu; Flowering; Fruiting; Phenophases; Semiarid

\section{Introdução}

Os estudos fenológicos analisam o desenvolvimento das plantas quanto aos seus eventos vegetativos e reprodutivos no decorrer de um período, bem como das relações desses eventos com fatores ambientais e bióticos (FOURNIER, 1974; LIETH; SCHULTZ, 1976; SILVA; SANTOS, 2008). Esses estudos são de extrema importância, uma vez que, a partir deles, muitos outros estudos envolvendo biologia reprodutiva, coleta de frutos e sementes, e dispersão de diásporos podem ser desenvolvidos. Portanto, a fenologia estuda a frequência, a intensidade, além do sincronismo de eventos denominados de fenofases, como o brotamento e a queda de folhas, a floração e a frutificação, fornecendo dados que permitem a análise da dependência destas fenofases com fatores bióticos e abióticos (NEWSTROM et al., 1994; ALMEIDA; ALVES, 2000; SANMARTINGAJARDO; MORELLATO, 2003; RAMOS; SANTOS, 2005; NEVES et al., 2010).

Além disto, diversos e importantes são os resultados dos estudos fenológicos, que podem ser utilizados no auxílio da produção de culturas agroflorestais, no combate às pragas, na recuperação de áreas degradadas e manejo de unidades de conservação, na criação de abelhas, enfim, para trabalhos que visem algum produto da planta, como coleta de frutos e sementes, além da relação entre planta-planta competindo por recursos ou por polinizadores (FOURNIER, 1974; MORELLATO, 1995; FISCH et al., 2000; NEVES et al., 2010).
Adicionalmente, a fenologia é uma das ferramentas básicas para o conhecimento biológico e ecológico de ecossistemas ou das espécies (BIONDI et al., 2007).

Sabe-se que o início e a duração das distintas fases de desenvolvimento de uma planta variam de ano para ano, dependendo das condições climáticas (LARCHER, 2000) e que essas condições climáticas, principalmente a quantidade de chuvas e a temperatura, influenciam significativamente o comportamento fenológico de uma espécie (PRAUSE; ANGELONI, 2000). Na caatinga e em florestas secas a quantidade de chuvas é considerada um fator crucial no desenvolvimento da maioria das plantas (MACHADO et al., 1997; BULHÃO; FIGUEIREDO, 2002) e poucos são os trabalhos desenvolvidos neste ecossistema sobre fenologia (MOURA, 2007), comparando-se à Mata Atlântica, por exemplo (SANMARTINGAJARDO; MORELLATO, 2003; GOULART et al., 2005; RAMOS et al., 2006).

Diante do exposto, esse trabalho teve como objetivos descrever o período das fenofases vegetativas e reprodutivas de seis espécies do estrato arbóreo em uma Unidade de Conservação do Semiárido potiguar, bem como a duração de cada fenofase; estimar o sincronismo das fenofases em cada espécie; e analisar se as fenofases apresentam correlação com a precipitação, temperatura e umidade relativa do ar. 


\section{Material e Métodos}

\section{Área de estudo}

O trabalho foi realizado na Floresta Nacional (FLONA), no município de Açu-RN, a qual segundo divisão do Instituto Brasileiro de Geografia e Estatística (IBGE), insere-se na microrregião do Vale do Açu. O município está localizado na região central do estado do Rio Grande do Norte, estendendo-se sob as coordenadas $5^{\circ} 34^{\prime} \mathrm{S}$ - 36 54'W, com uma altitude média de $100 \mathrm{~m}$ (COSTA et al., 2010). A Floresta Nacional de Açu FLONA/Açu representa um remanescente de floresta de caatinga, com vegetação do tipo arbóreo-arbustiva aberta, tendo ainda preservada boa parte de suas características originais, constituindo uma das poucas Unidades de Conservação desse ecossistema no estado.

O clima, segundo a classificação de Köppen (1948) é considerado "Bswh", semiárido, ou seja, seco, muito quente e com chuvas irregulares e concentradas geralmente entre os meses de dezembro a abril, com uma média anual de $600 \mathrm{~mm}$ (COSTA et al., 2010). Contudo, há épocas em que essa região pode apresentar deficiência hídrica durante a maior parte do ano, bem como chuvas esporádicas no período de seca, e pequenos veranicos na época chuvosa. Além do mais, a temperatura média anual é de $28,1^{\circ} \mathrm{C}$ e a umidade relativa compreende até $70 \%$. Segundo Ferreira (1988), a FLONA/Açu apresenta dois tipos de solo, sendo um considerado litólico, com cascalho de quartzo arredondado, e outro de areia quartzosa, ambos classificados como neossolos.

\section{Observações fenológicas e análise}

\section{dos dados}

Para o acompanhamento fenológico, cinco indivíduos de cada uma das seis espécies arbóreas foram selecionados, sendo elas: Dipteryx odorata (Aubl.) Willd. (Fabaceae) - Cumaru, Cordia oncocalyx Allemão (Boraginaceae) - Pau Branco, Poincianella pyramidalis (Tul.) L.P. Queiroz (Fabaceae) - Catingueira, Manihot pseudoglaziovii Pax \& K. Hoffm. (Euphorbiaceae) Maniçoba, Handroanthus heptaphyllus (Vell.) Mattos (Bignoniaceae) - Ipê Roxo, e Pseudobombax cf. marginatum (A. St.-Hil., Juss. \& Cambess.) A. Robyns
(Malvaceae) - Embiratanha. Essas espécies foram selecionadas devido à importância ecológica e pela representatividade de indivíduos na área de estudo.

Durante um período de vinte e cinco (25) meses (Dezembro de 2007 a Dezembro de 2009), viagens quinzenais foram realizadas ao local de estudo para monitoramento das fenofases vegetativas: brotamento de novas folhas e queda foliar; e das fenofases reprodutivas: florescimento, considerando botões florais ou inflorescências presentes, floração adiantada ou totalmente florida, floração terminada ou terminando, e frutificação, considerando a presença de frutos imaturos, maduros ou em fase de dispersão. As observações das fenofases incluíram os períodos seco e chuvoso, e em todas as viagens de coleta de dados, observaram-se os aspectos reprodutivos e vegetativos de cada espécie, anotando-se todos os dados e obtendo-se os registros fotográficos para comparações possíveis de cada fenofase.

Para isso, utilizaram-se dois métodos de avaliação, um qualitativo (FOURNIER, 1974; BENCKE; MORELLATO, 2002a), que se aplica a observação direta das plantas, definindo apenas a presença ou ausência da fenofase em questão, considerando-se o período da fenofase desde quando, pelo menos, um indivíduo manifestava o evento biológico até o último indivíduo deixar de manifestá-lo (SILBERBAUERGOTTSBERGER, 2001). E ainda, segundo Bencke e Morellato (2002b), outro método semiquantitativo, com o qual se verificou o índice de atividade, que avalia o número de indivíduos que manifestam determinada fenofase, identificando a sincronia dos eventos fenológicos entre as espécies. Para isso, o evento fenológico foi considerado: assincrônico $(<20 \%$ de indivíduos na fenofase); pouco sincrônico ou com baixa sincronia (20-60\% de indivíduos na fenofase); e de sincronia alta ( $>60 \%$ dos indivíduos na fenofase) (ver também MARCHIORETTO et al., 2007).

Para analisar o quanto cada fenofase se expressou em um período de tempo, ou seja, a amplitude de tempo, em meses, de cada evento vegetativo ou reprodutivo, utilizou-se a metodologia proposta por Newstrom et al. (1994), que reconhece três classes diferentes: uma curta, na qual o evento tem duração de até um mês; uma intermediária, com a fenofase se estendendo de 
dois a cinco meses; e uma longa, na qual a fenofase se estenderia por seis meses ou mais.

Para verificar a correlação entre o desenvolvimento das fenofases e os fatores abióticos, foi utilizado o coeficiente de correlação de Spearman - $\rho$, que é recomendado para dados que não apresentam distribuição normal (ZAR, 1999), sendo analisados os seguintes dados meteorológicos: precipitação $(\mathrm{mm})$, temperatura $\left({ }^{\circ} \mathrm{C}\right)$ e umidade relativa do ar (\%) (Figura 1A e 1B). Estes dados foram obtidos diariamente, apresentando uma média mensal, e fornecidos pela Estação Ipanguaçu, base física da Empresa de Pesquisa Agropecuária do Rio Grande do Norte (EMPARN), localizada no município de Ipanguaçu - RN, a aproximadamente $12 \mathrm{~km}$ da área de estudo.

FIGURA 1: Registro mensal da precipitação e da temperatura (A), e da umidade relativa do ar e temperatura (B) anual durante os meses de dezembro de 2007 - dezembro de 2009. Floresta Nacional de Açu/RN (FLONA - Açu/ RN), Nordeste do Brasil.

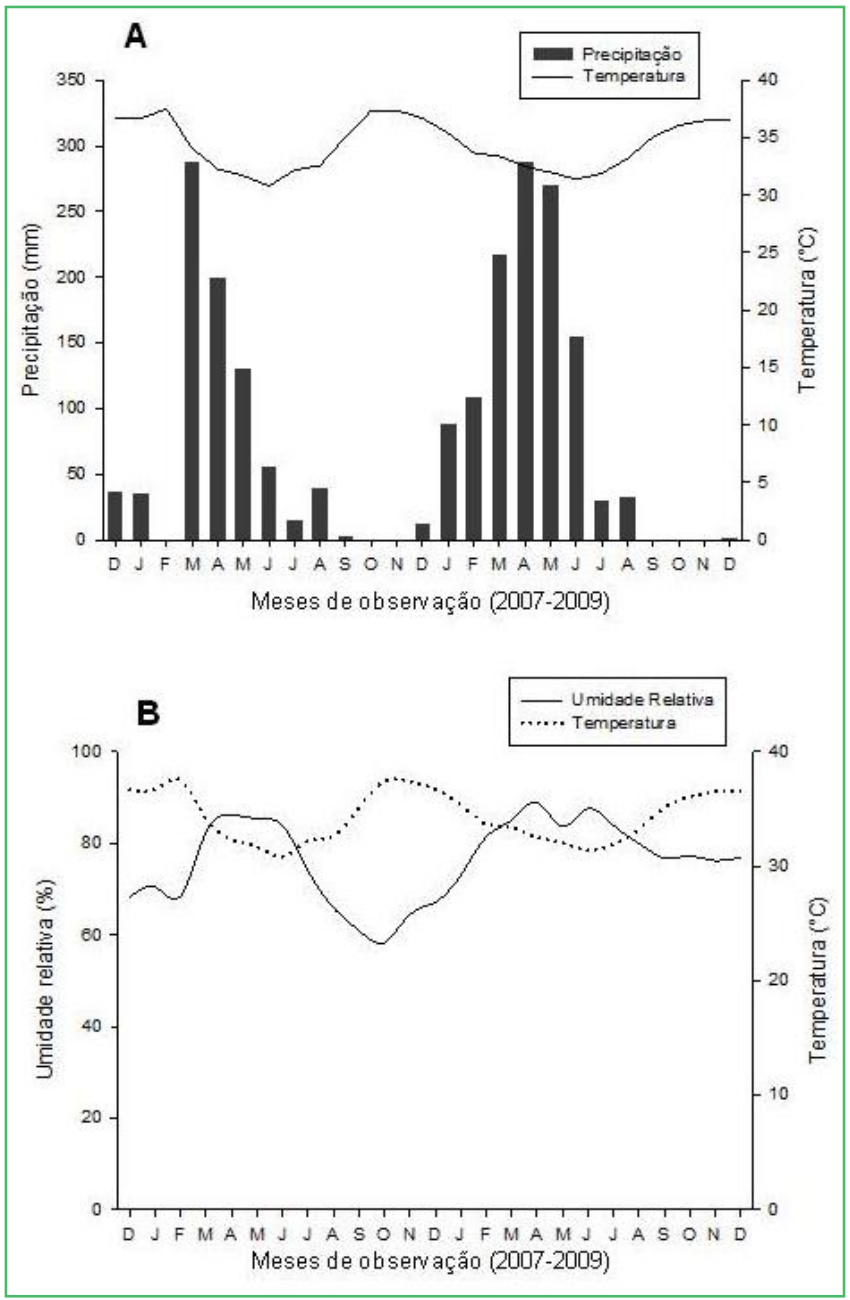

\section{Resultados e Discussão}

\section{Brotamento de novas folhas e queda foliar}

Todas as espécies tiveram um comportamento decíduo, ou seja, apresentaram brotamento de novas folhas no início do período chuvoso, estendendo-se durante esse período, e perderam suas folhas no período seco. No entanto, Cordia oncocalyx e Poincianella pyramidalis iniciaram a queda foliar de maneira concentrada no final da estação seca, enquanto as outras espécies perderam suas folhas no final da estação chuvosa e início da seca (Figura 2). Esta tendência das árvores de ambientes secos já foi apontada não apenas para a caatinga (BARBOSA et al., 2003; MAIA, 2004), como também para o cerrado, onde as plantas apresentaram suas fenofases vegetativas reguladas principalmente pela precipitação (DUTRA, 1987).

Quanto ao tempo ocorrente da fenofase brotamento de novas folhas, $P$. pyramidalis apresentou maior amplitude desta fenofase, com um total de oito a nove meses por ciclo fenológico (Figura 2). Além do mais, as espécies estudadas apresentaram uma alta sincronia quanto ao brotamento, com todos os indivíduos (100\%) iniciando e finalizando no período de pico desta fenofase (Figura 3).

O fato das espécies apresentarem uma alta sincronia no brotamento de novas folhas pode ser atribuído à disponibilidade hídrica, por meio da precipitação no início da estação chuvosa, pois todas as espécies, tanto as decíduas quanto as perenes aguardam por essa disponibilidade para ativar seus mecanismos de produção foliar, pelo menos de forma mais intensa. Assim, quanto mais cedo elas produzem ou renovam suas folhas, mais energia podem captar para seguirem com sua reprodução (ARAÚJO et al., 2008). Em área de caatinga, também se verificou que nas árvores locais há maior sincronismo na fenofase de brotamento foliar (AMORIM et al., 2009). Esses mesmos autores observaram ainda, que, a fenofase de brotamento de novas folhas foi mais curta do que todas as outras fenofases na área, pois as espécies da caatinga apresentam uma rápida resposta fisiológica ao serem estimuladas pela chuva. Já na FLONA/Açu, 
FIGURA 2: Fenofases e períodos observados: brotamento de novas folhas ( $\square$ ); queda foliar ( $\square$ ); florescimento ( $\square$ ); e frutificação ( $\square$ ). Floresta Nacional de Açu/RN (FLONA-Açu/RN), Nordeste do Brasil. Dezembro de 2007 a dezembro de 2009.

\section{CATINGUEIRA - Poincianella pyramidalis}
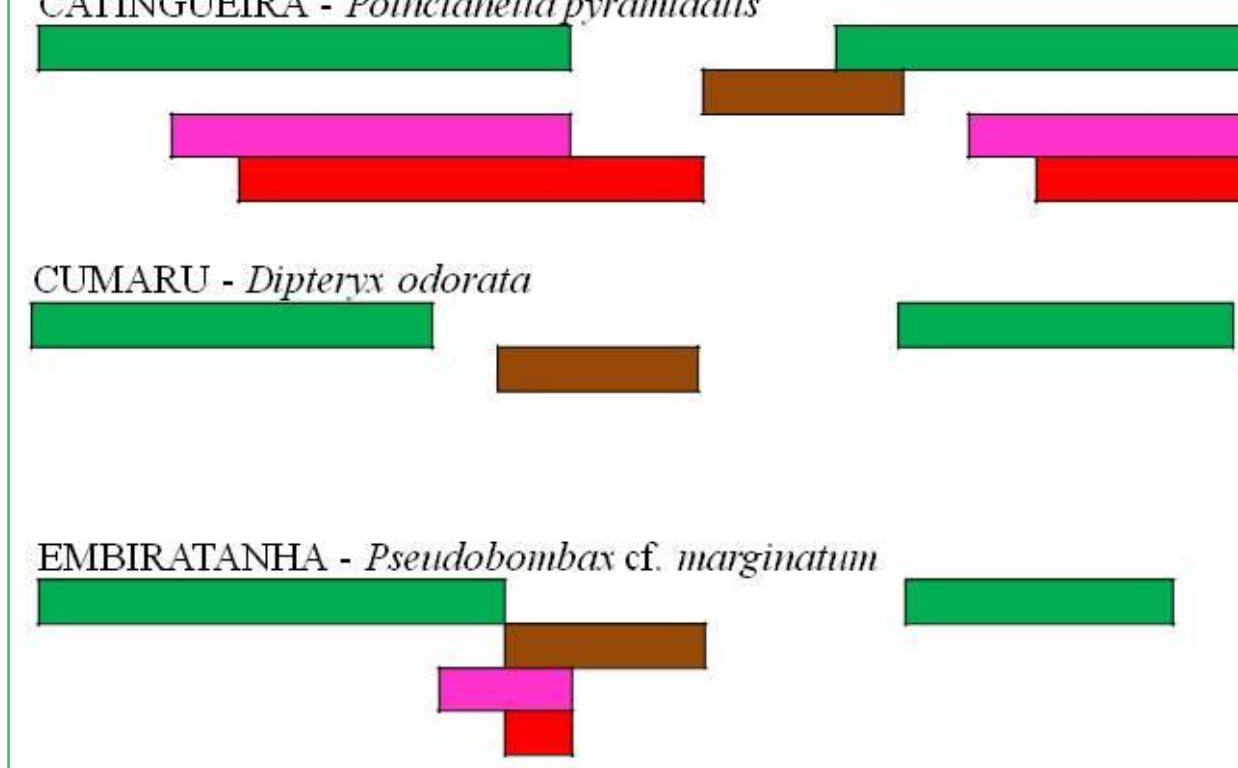

IPE-ROXO - Handroanthis heptaphylla
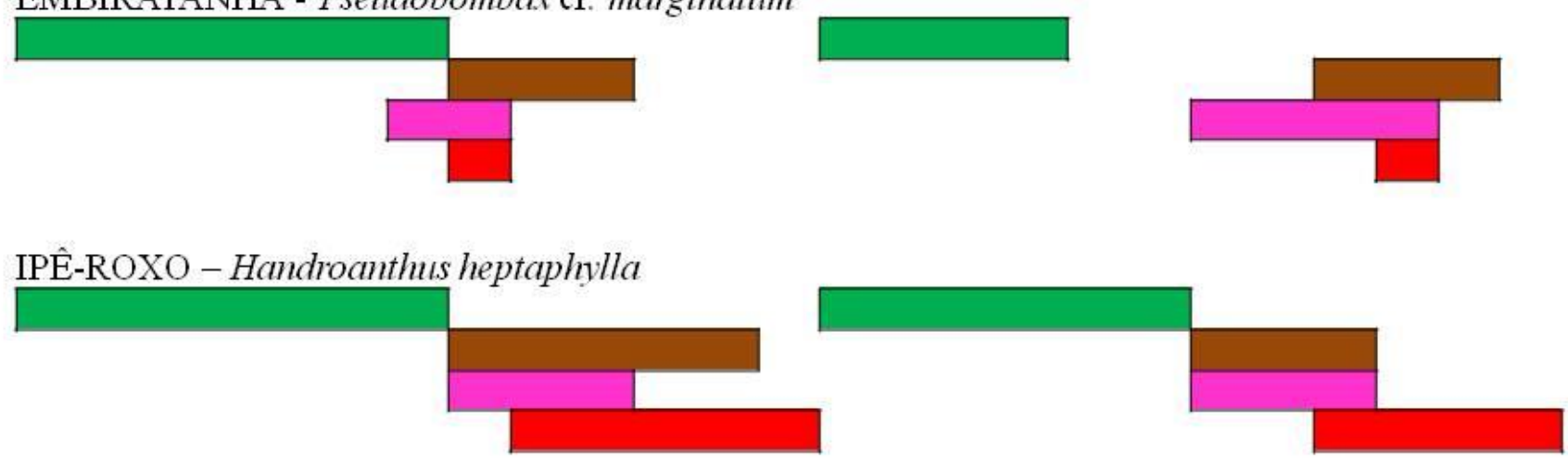

MANIÇOBA - Manihot pseudoglaziovii
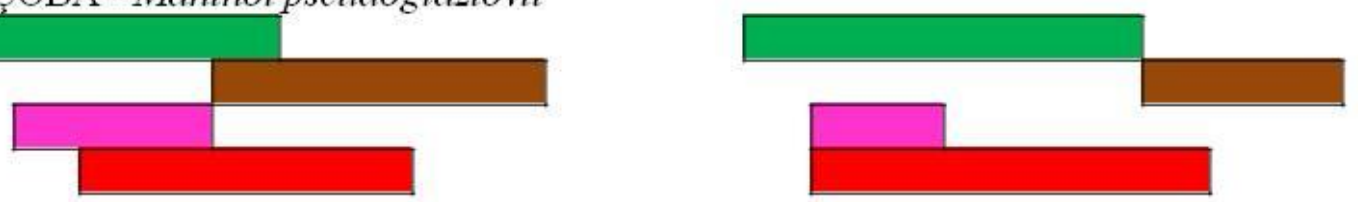

PAU BRANCO - Cordia oncocalyx

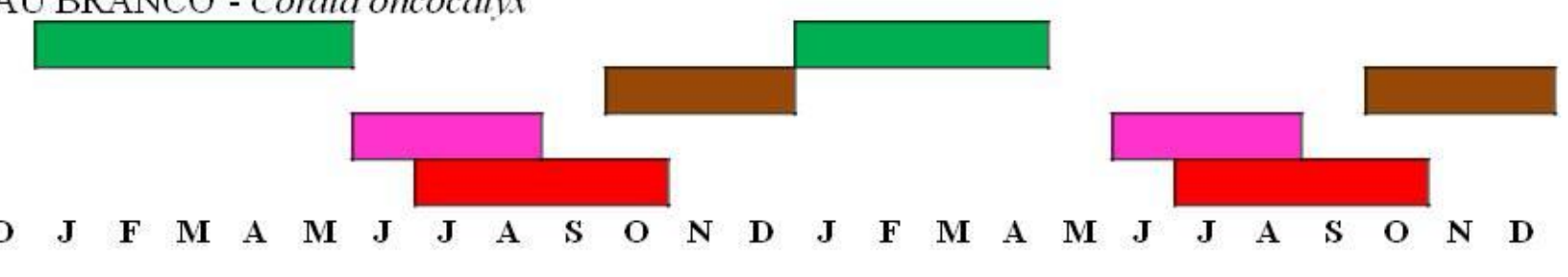


FIGURA 3: Porcentagem de indivíduos de cada espécie manifestando as fenofases de brotamento de novas folhas (linha contínua) e queda foliar (linha tracejada), de dezembro de 2007 a dezembro de 2009. Floresta Nacional de Açu/RN (FLONA/Açu - RN), Nordeste do Brasil.

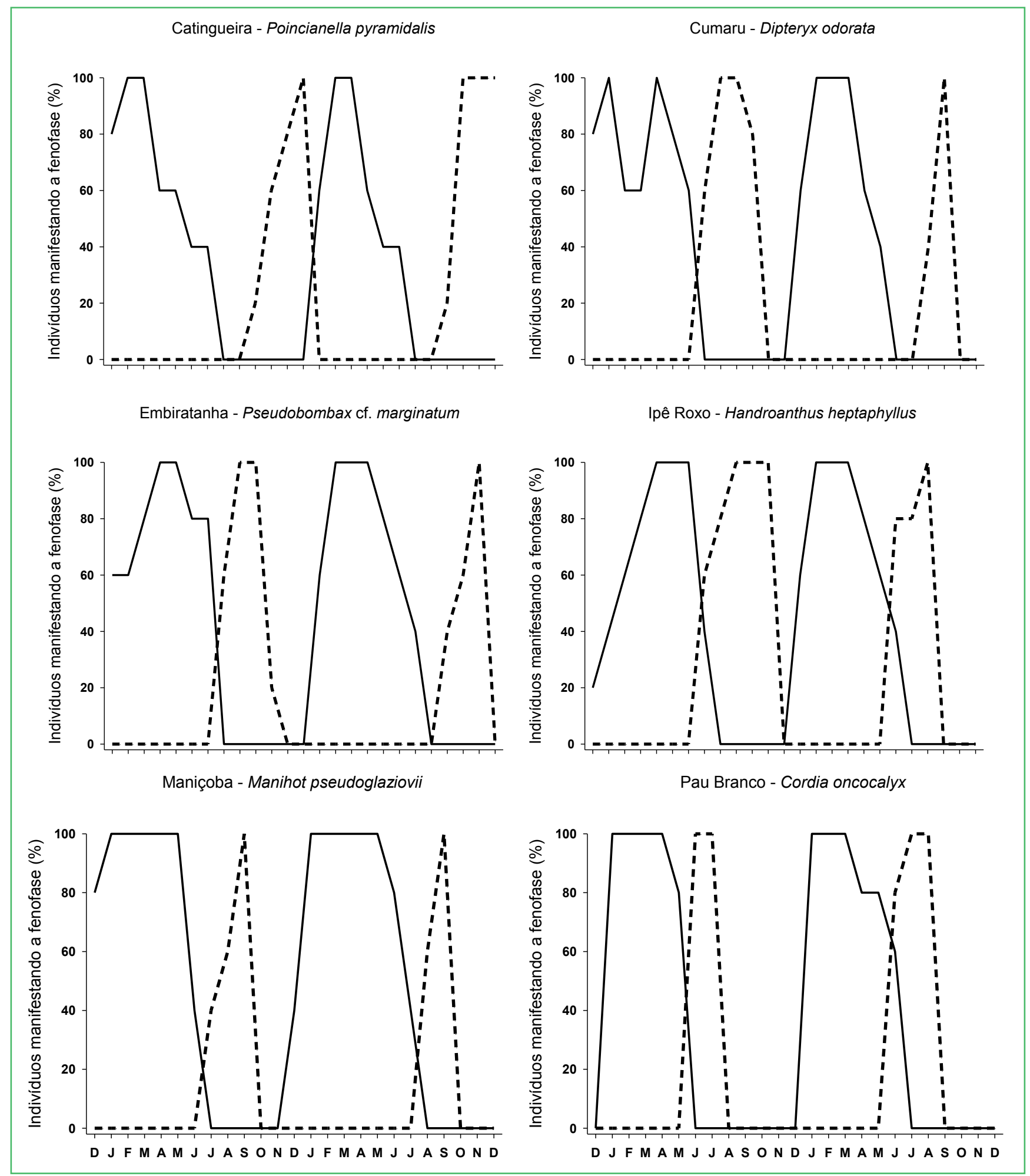


em que ocorreu um maior índice de precipitação no período monitorado, em relação aos anos anteriores e às outras áreas de caatinga hiperxerófila, o brotamento de novas folhas foi a fenofase que mais se estendeu, acompanhando a precipitação ao longo do ano e apresentando uma correlação positiva para todas as espécies estudadas (Tabela 1).

Quanto à queda foliar, $H$. heptaphyllus e $M$. pseudoglaziovii apresentaram esta fenofase por cinco meses no primeiro ciclo fenológico e, no ciclo seguinte, reduziram esse tempo para apenas três meses. As demais espécies perderam suas folhas durante três meses nos dois ciclos, com exceção apenas para $D$. odorata, que perdeu suas folhas em um curto período de dois meses, durante o segundo ciclo (Figura 2). Em relação ao sincronismo, todas as espécies apresentaram $100 \%$ de seus indivíduos perdendo suas folhas em um determinado período, com destaque para $P$. pyramidalis, que iniciou esta fenofase nos dois ciclos, com apenas $20 \%$ de seus indivíduos (Figura 3 ). Isto pode ter ocorrido por alguns motivos, dentre os quais, a disponibilidade de água no solo para esta espécie, e o acúmulo de água em seus tecidos de reserva (MORELATTO et al., 1989; LIMA; RODAL, 2010).
As espécies $P$. pyramidalis, D. odorata, $C$. oncocalyx, $H$. heptaphyllus e $P$. marginatum também compartilham em outras localidades de caatinga essa alta sincronia em suas fenofases vegetativas, principalmente associadas ao período mais favorável (BARBOSA et al., 1989; MAIA, 2004, AMORIM et al., 2009, SIQUEIRA FILHO et al., 2010). Em área de floresta de galeria, com clima subtropical seco e com média de precipitação maior que na caatinga hiperxerófila, verificou-se também que as fenofases vegetativas das árvores estudadas acompanham o ritmo da precipitação e da temperatura local (JUSTINIANO; FREDERICKSEN, 2000).

Todas as espécies apresentaram correlação positiva significativa entre o brotamento foliar e a precipitação e somente $P$. marginatum e $H$. heptaphyllus exibiram uma correlação positiva e significativa entre esta fenofase e a umidade relativa do ar. No entanto, apenas H. heptaphyllus demonstrou uma pequena correlação negativa significativa entre o brotamento e a temperatura (Tabela 1). Já para a queda foliar, não houve correlação significativa com a umidade do ar para nenhuma espécie, contudo, apenas para $P$. pyramidalis e $C$. oncocalyx, houve uma correlação significativa negativa entre a precipitação e a queda das folhas e correlação positiva

TABELA 1: Correlação de Spearman $(\rho)$ entre as variáveis ambientais (precipitação, temperatura e umidade relativa) e as fenofases de brotamento de novas folhas (bnf), floração (flor), frutificação (frut) e queda foliar (qf) de espécies arbóreas de caatinga, FLONA/Açu, RN. $(* p=0,01 ; * * p<0,01 ; * * * p<0,001$; NS = não significativo, [-] ausência de fenofase).

\begin{tabular}{|c|c|c|c|c|c|c|c|c|c|c|c|c|}
\hline \multicolumn{13}{|c|}{ Correlação de Spearman ( $\rho)$} \\
\hline & \multicolumn{4}{|c|}{ Precipitação (mm) } & \multicolumn{4}{|c|}{ Temperatura $\left({ }^{\circ} \mathrm{C}\right)$} & \multicolumn{4}{|c|}{ Umidade Relativa (\%) } \\
\hline ESPÉCIES & bnf & qf & flor & frut & bnf & qf & flor & frut & bnf & $\mathrm{qf}$ & flor & frut. \\
\hline \multirow{2}{*}{$\begin{array}{l}\text { Poincianella } \\
\text { pyramidalis }\end{array}$} & 0,61 & $-0,73$ & 0,62 & 0,49 & $-0,0156$ & 0,56 & $-0,80$ & $-0,87$ & 0,34 & $-0,46$ & 0,84 & 0,53 \\
\hline & $* * *$ & $* * *$ & $* * *$ & $*$ & NS & $* *$ & $* * *$ & $* * *$ & NS & $*$ & $* * *$ & $* *$ \\
\hline \multirow{2}{*}{ Dipteryx odorata } & 0,72 & $-0,44$ & - & - & $-0,20$ & 0,09 & - & - & 0,50 & $-0,47$ & - & - \\
\hline & $* * *$ & NS & - & - & NS & NS & - & - & $*$ & $*$ & - & - \\
\hline \multirow{2}{*}{$\begin{array}{l}\text { Pseudobombax cf. } \\
\text { marginatum }\end{array}$} & 0,80 & $-0,52$ & $-0,34$ & $-0,27$ & $-0,36$ & 0,11 & $-0,08$ & 0,11 & 0,65 & $-0,45$ & 0,12 & 0,03 \\
\hline & $* * *$ & $* *$ & NS & NS & NS & NS & NS & NS & $* * *$ & NS & NS & NS \\
\hline \multirow{2}{*}{$\begin{array}{l}\text { Handroanthus } \\
\text { heptaphyllus }\end{array}$} & 0,79 & $-0,52$ & $-0,39$ & $-0,68$ & $-0,55$ & 0,10 & $-0,14$ & 0,42 & 0,72 & $-0,49$ & $-0,18$ & $-0,54$ \\
\hline & $* * *$ & * & NS & $* * *$ & $* *$ & NS & NS & NS & $* * *$ & $*$ & NS & $* *$ \\
\hline \multirow{2}{*}{$\begin{array}{c}\text { Manihot } \\
\text { pseudoglaziovii }\end{array}$} & 0,73 & $-0,25$ & 0,65 & 0,67 & $-0,20$ & $-0,13$ & $-0,32$ & $-0,83$ & 0,50 & $-0,31$ & 0,63 & 0,83 \\
\hline & $* * *$ & NS & $* * *$ & $* * *$ & NS & NS & NS & $* * *$ & * & NS & $* * *$ & $* * *$ \\
\hline \multirow{2}{*}{ Cordia oncocalyx } & 0,62 & $-0,60$ & 0,04 & $-0,46$ & $-0,08$ & 0,56 & $-0,57$ & $-0,01$ & 0,40 & $-0,39$ & 0,30 & $-0,34$ \\
\hline & $* * *$ & $* * *$ & NS & NS & NS & $* *$ & $* *$ & NS & NS & NS & NS & NS \\
\hline
\end{tabular}


entre essa fenofase e a temperatura. A espécie $P$. marginatum apresentou também uma pequena correlação negativa entre a queda foliar e a precipitação (Tabela 1).

Em relação à queda foliar, Morellato et al. (1989) relataram que esta fenofase não depende somente da precipitação, mas também da quantidade de água que o solo consegue armazenar, demonstrando que apenas 50\% das espécies trabalhadas apresentaram uma correlação positiva entre a precipitação e a queda foliar. Outro fator que também pode atenuar a correlação da precipitação com a queda foliar é a densidade da madeira. Isto foi observado por Lima e Rodal (2010), inclusive com espécies dos gêneros Manihot, Poincianella e Dipteryx também em área de caatinga.

Outro fato importante é que a manifestação das fenofases de árvores em ambientes secos tende a ser sazonal, uma vez que mesmo a partir de chuvas esporádicas durante o período seco, nem sempre as espécies conseguem dar continuidade aos seus eventos biológicos, naquele período, ou nem mesmo os iniciam (MACHADO et al., 1997). Isto também tem sido observado em ambientes úmidos, nos quais as plantas não sofrem com tanta falta de recurso, a depender do período analisado (TALORA; MORELLATO, 2000).

\section{Floração e frutificação}

Dipteryx odorata foi a única espécie que não floresceu nem frutificou durante todo o período analisado, enquanto todas as outras espécies tiveram seus momentos de floração e frutificação verificáveis, com algumas variações. Maia (2004) enfatizou que, em plantios manejados, esta espécie só apresentou suas fenofases reprodutivas em indivíduos com 10 anos de idade. Logo, os indivíduos que foram acompanhados poderiam ainda não estar em idade reprodutiva, ou até mesmo apresentar um intervalo maior do que observado entre suas manifestações reprodutivas.

Observou-se que P.pyramidalis e M. pseudoglaziovii floresceram logo no início da estação chuvosa, ao passo que $P$. marginatum, $H$. heptaphyllus e $C$. oncocalyx apresentaram essa fenofase no final desta estação (Figura 2). Tem-se acompanhado que a tendência das lenhosas de ambientes secos é que estas floresçam em meados ou no final da estação chuvosa (DUTRA, 1987; MAIA, 2004; AMORIM et al., 2009).

Quanto à duração da floração, $P$. pyramidalis foi a única a pertencer à classe longa, apresentando um tempo superior a seis meses. Enquanto que as outras espécies foram inseridas na classe intermediária, sendo P. marginatum a que apresentou um máximo de quatro meses florindo em um dos ciclos fenológicos, e $H$. heptaphyllus, $M$. pseudoglaziovii e $C$. oncocalyx com um pico de até três meses (Figura 2). Em ambiente de caatinga no Ceará, Maia (2004) relatou que a $C$. oncocalyx floresce ainda na primeira metade da época chuvosa, dois meses após o início das chuvas, e se estende por apenas um mês. Logo, mesmo as lenhosas podem sofrer variação nessa fenofase reprodutiva, dependendo dos fatores ambientais locais, que podem ser mais ou menos severos.

Verificou-se que P. pyramidalis, M. pseudoglaziovii e $C$. oncocalyx tiveram uma alta sincronia em suas florações, apresentando $100 \%$ dos indivíduos manifestando a fenofase. Já para $P$. marginatum e $H$. heptaphyllus, a fenofase em questão foi considerada pouco sincrônica ou de baixa sincronia, pois as mesmas apresentaram até $40 \%$ e $60 \%$ de seus indivíduos floridos, respectivamente (Figura 4). O fato de duas espécies não terem $100 \%$ de sincronia quanto floração não é muito divulgado em ambientes secos, quando geralmente as plantas aproveitam a estação mais favorável para iniciar sua floração (BULLOCK; SOLIS-MAGALLANES, 1990; JUSTINIANO; FREDERICKSEN, 2000).

Dentre todas as espécies estudadas, $P$. pyramidalis, M. pseudoglaziovii, H. heptaphyllus e C. oncocalyx apresentaram algum tipo de correlação entre as fenofases reprodutivas com os fatores abióticos estudados. Poincianella pyramidalis apresentou correlação significativa positiva entre a floração e as variáveis precipitação e umidade relativa do ar, e correlação significativa negativa entre a floração e a temperatura. Manihot pseudoglaziovii apenas registrou uma correlação significativa positiva com duas variáveis, precipitação e umidade relativa do ar. Já C. oncocalyx apresentou correlação negativa entre floração e temperatura (Tabela 1). 
FIGURA 4: Porcentagem de indivíduos de cada espécie manifestando as fenofases de floração (linha contínua) e frutificação (linha tracejada), de dezembro de 2007 a dezembro de 2009. Floresta Nacional de Açu (FLONA/Açu - RN), Nordeste do Brasil.

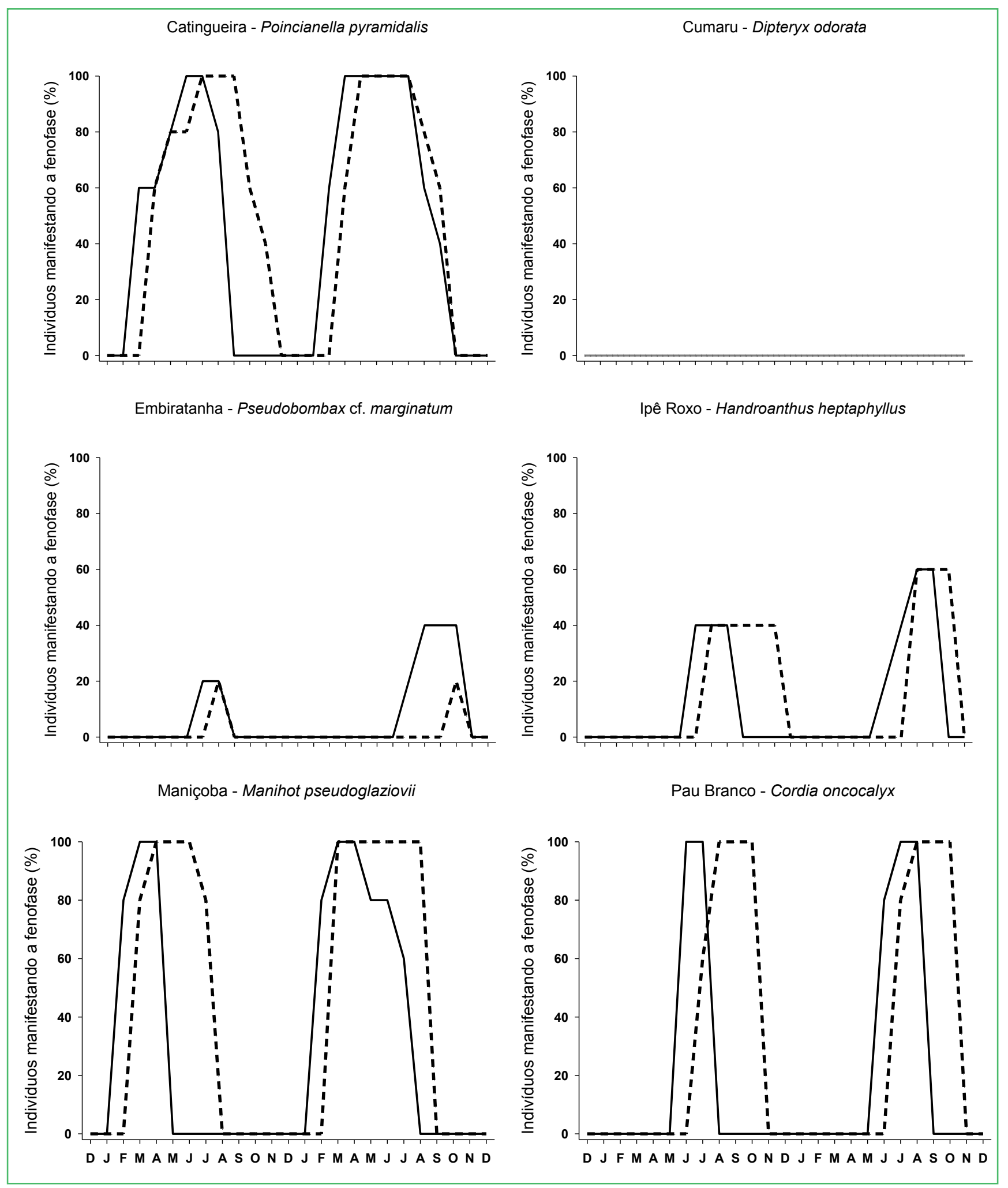


Vários estudos realizados em áreas sazonalmente secas apontaram que a floração tende a acontecer no período chuvoso, sugerindo que o fator chuva pode apresentar uma expressiva correlação com esta fenofase (LAMPE et al., 1992; MACHADO et al., 1997; JUSTINIANO; FREDERICKSEN, 2000; LESICA; KITTELSON, 2010; TORRES; GALETTO, 2011). Contudo, no trabalho de Lima e Rodal (2010), apenas $37 \%$ das espécies apresentaram correlação positiva entre a floração e a precipitação, semelhante ao encontrado para a caatinga da FLONA/Açu, em que cerca de 33\% das espécies apresentou correlação positiva entre esse fator e essa fenofase. Isto porque, segundo Lima e Rodal (2010), algumas espécies não dependem primariamente da precipitação para iniciar suas fenofases, pois estas apresentam características próprias de acúmulo de água e podem, inclusive, iniciarem sua floração no período menos favorável.

Para a frutificação observou-se que $P$. pyramidalis e M. pseudoglaziovii manifestaram essa fenofase ainda no início da estação chuvosa. Verificaram-se indivíduos de $M$. pseudoglaziovii frutificando durante esta estação até o início do período seco, e indivíduos de P. pyramidalis frutificando até meados da seca. Já para P. marginatum, a frutificação ocorreu apenas em um mês durante o primeiro ciclo fenológico, considerado como início de período seco, e em um mês novamente no segundo ciclo, porém, no meio da estação seca. Enquanto que para $H$. heptaphyllus e $C$. oncocalyx, o período de frutificação estendeu-se de quatro a cinco meses da estação seca.

Quanto à amplitude de frutificação, a $P$. pyramidalis foi a única a pertencer à classe longa, com até oito meses apresentando frutos. Em seguida, aparecem $H$. heptaphyllus, $M$. pseudoglaziovii e $C$. oncocalyx na classe intermediária, com até cinco meses frutificando e por fim, a espécie P. marginatum faz parte da classe curta, pois o evento reprodutivo em questão foi visto em apenas um mês (Figura 2). Similar à floração, verificou-se que $P$. pyramidalis, $M$. pseudoglaziovii e C. oncocalyx tiveram uma alta sincronia em sua frutificação, apresentando $100 \%$ dos indivíduos manifestando a fenofase. Já para P. marginatum e H. heptaphyllus, a fenofase em questão foi considerada pouco sincrônica ou de baixa sincronia, pois as mesmas só apresentaram até $40 \%$ e $60 \%$ de seus indivíduos com frutos, respectivamente (Figura 4).

Em outras áreas de florestas secas sazonais, a frutificação tende a ser contínua ao longo dos estudos (LAMPE et al., 1992; MACHADO et al., 1997; JUSTINIANO; FREDERICKSEN, 2000; GRIZ; MACHADO, 2001), ou seja, com espécies manifestando essa fenofase no início, meio ou final do período chuvoso, e outras espécies no início ou final da estação seca, enquanto Lima e Rodal (2010) verificaram que maior número de espécies frutifica no início da estação chuvosa, sendo esta indicadora do comportamento sazonal das espécies.

Assim como ocorreu na fenofase floração, $P$. pyramidalis apresentou uma correlação significativa negativa entre a frutificação e a temperatura, e uma correlação significativa positiva entre esta fenofase e a umidade relativa do ar, contudo, não apresentou correlação com a precipitação. Em $H$. heptaphyllus observou-se uma correlação significativa negativa entre a frutificação e a precipitação e para a M.pseudoglaziovii houve correlação significativa para as três variáveis ambientais, sendo positiva para a precipitação e a umidade relativa do ar, para o florescimento e a frutificação, e negativa para a temperatura, apenas na frutificação (Tabela 1).

Semelhante ao trabalho de Amorim et al. (2009), nesse estudo as fenofases de floração e frutificação foram mais ocorrentes durante o período chuvoso, com a floração seguindo o fluxo de folhas e a frutificação se estendendo até o período de queda foliar, embora apenas duas espécies tenham apresentado alguma correlação entre a chuva e essas fenofases.

Por fim, as espécies estudadas aqui compartilham as mesmas tendências fenológicas vistas para outras áreas de florestas secas. Porém, como houve um maior índice de precipitação do que em outras áreas no período acompanhado, algumas espécies tenderam a estender algumas de suas fenofases. Desse modo, evidenciou-se que as fenofases apresentaram correlações significativas com fatores abióticos, principalmente com a precipitação. 


\section{Agradecimentos}

Ao CNPq pela concessão da bolsa de Iniciação Científica (IC) ao primeiro Autor e bolsa de Produtividade em Pesquisa a J.I.M. Melo (Proc. no $0.302751 / 2012-2$ ); à Universidade do Estado do Rio Grande do Norte (UERN) por todo apoio prestado a este estudo; aos funcionários da FLONA-Açu/RN pela ajuda inclusive pelas informações prestadas, em especial ao Irmão (Dedé) pela solicitude; e aos pesquisadores do Laboratório de Ecologia e Sistemática Vegetal (LESV/UERN).

\section{Referências}

ALMEIDA, E. M.; ALVES, M. A. S. Fenologia de Psychotria nuda e $P$. brasiliensis (Rubiaceae) em uma área de Floresta Atlântica do sudeste do Brasil. Acta Botanica Brasilica, São Paulo, v. 14, p. 335-346, 2000.

AMORIM, I. L.; SAMPAIO, E. V. S. B.; ARAÚJO, E. L. Fenologia de espécies lenhosas da caatinga do Seridó, RN. Revista Árvore, Viçosa, v. 33, n. 3, p. 491-499, 2009.

ARAÚJO, E. L.; NOGUEIRA, R. J. M. C.; SILVA, S. I.; SILVA, K. A.; SILVA, P. P. A.; SANTOS, A. V. C.; SANTIAGO, G. A. S. Ecofisiologia de plantas da caatinga e implicações com a dinâmica das populações e do ecossistema. In: MOURA, A. N.; ARAÚJO, E. L.; ALBUQUERQUE, U. P. (Ed.). Biodiversidade, potencial econômico e processos eco-fisiológicos em ecossistemas nordestinos. Vol. 1. Bauru: Canal6, 2008. p. 327-361.

BARBOSA, D. C. A.; ALVES, J. L. H.; PRAZERES, S. M.; PAIVA, A. M. A. Dados fenológicos de 10 espécies arbóreas de uma área da Caatinga (Alagoinha-PE). Acta Botanica Brasilica, São Paulo, v. 3, n. 2, p. 109-117, 1989.

BARbosA, D. C. A.; BARbosA, M. C. A.; LIMA, L. C. M. Fenologia de espécies lenhosas da caatinga. In: LEAL, I. R.; TABARELLI, M.; SILVA, J. M. C. (Ed.). Ecologia e conservação da Caatinga. Recife, UFPE. 2003. p. 657-693.

BENCKE, C. S. C.; MORELlATO, L. P. C. Comparação de dois métodos de avaliação da fenologia de plantas, sua interpretação e representação. Revista Brasileira de Botânica, São Paulo, v. 25, n. 3, p. 269-275, 2002a.

BENCKE, C. S. C.; MORELLATO, L. P. C. Estudo comparativo da fenologia de nove espécies arbóreas em três tipos de floresta atlântica no sudeste do Brasil. Revista Brasileira de Botânica, São Paulo, v. 25, n. 2, p. 237-248, 2002 b.

BIONDI, D.; LEAL, L.; BATISTA, A. C. Fenologia do florescimento e frutificação de espécies nativas dos Campos. Acta Scientiarum Biological Sciences, Maringá, v. 29, n. 3, p. 269-276, 2007.

BULHÃO, C. F.; FIGUEIREDO, P. S. Fenologia de leguminosas arbóreas em uma área de cerrado marginal no nordeste do Maranhão. Revista Brasileira de Botânica, São Paulo, v. 25, p. 361-369, 2002.

BULLOCK, S. H.; SOLIS-MAGALLANES, J. A. Phenology of canopy trees of a tropical deciduous forest in Mexico. Biotropica, Zurich, v. 22, p. 22-35, 1990.
COSTA, C. C. A.; DANTAS, I. M.; CAMACHO, R. G. V.; SILVA, P. C. M. Análise comparativa da produção de serapilheira em fragmentos arbóreos e arbustivos em área de caatinga na FLONA de Açu-RN. Revista Árvore, Viçosa, v. 34, p. 259-265, 2010.

DUTRA, R. C. Fenologia de dez espécies arbóreas nativas do cerrado de Brasília-DF. Brasil Florestal, Brasília, v. 62, p. 23-41, 1987.

FERREIRA, L. C. Análise estrutural da vegetação da Estação Florestal de Experimentação de Assú - RN, como subsídio básico para o manejo florestal. 1988. 91 f. Dissertação (Mestrado em Ecologia) - Universidade Federal de Viçosa, Viçosa. 1988.

FISCH, S. T. V.; NOGUEIRA JÚNIOR, L. R.; MANTOVANI, W. Fenologia reprodutiva de Euterpe edulis Mart. na Mata Atlântica (Reserva Ecológica do Trabiju, Pindamonhangaba-SP). Revista Biociências, Taubaté, v. 6, n. 2, p. 31-37, 2000.

FOURNIER, L. A. Un método cuantitativo para la medición de características fenológicas en árboles. Turrialba, San José, v. 25, n. 4, p. 422-423, 1974.

GOUlart, M. F.; Lemos Filho, J. P.; LOVATO, M. B. Phenological variation within and among populations of Plathymenia reticulata in Brazilian Cerrado, the Atlantic Forest and transitional sites. Annals of Botany, Oxford, v. 96, p. 445-455, 2005.

GRIZ, L. M. S.; MACHADO, I. C. S. Fruiting phenology and seed dispersal syndromes in caatinga, a tropical dry forest in the northeast of Brazil. Journal of Tropical Ecology, Winchelsea, v. 17, p. 303-321, 2001.

JUSTINIANO, J. M.; FREDERICKSEN, T. S. Phenology of tree species in Bolivian dry forests. Biotropica, Zurich, v. 32, p. 276$281,2000$.

KÖPPEN, W. Climatologia: con un estúdio de los climas de la tierra. México: Fondo de Cultura Económica, 1948. 466 p.

LAMPE, M. G.; BERGERON, Y.; MCNEIL, R.; LEDUC, A. Seasonal flowering and fruiting patterns in tropical semi-arid vegetation of northeastern Venezuela. Biotropica, Zurich, v. 24, p. 64-76, 1992.

LARCHER, W. Ecofisiologia vegetal. São Carlos: Rima - Artes e Textos. 2000. 531 p.

LESICA, P.; KITTELSON, P. M. Precipitation and temperature are associated with advanced flowering phenology in a semi-arid grassland. Journal of Arid Environments, London, v. 74, p. 1013 $1017,2010$.

LIETH, H.; SCHULTZ, G. Contribuitions from biometeorological workshops focusing on seasonality. Journal of Biogeography, New York, v. 3, p. 229, 1976

LIMA, A. L. A.; RODAL, M. J. N. Phenology and wood density of plants growing in the semi-arid region of northeastern Brazil. Journal of Arid Environments, London, v. 74, n. 11, p. 1363 1373,2010 .

MACHADO, I. C. S.; BARROS, L. M.; SAMPAIO, E. V. S. B. Phenology of caatinga at Serra Talhada, PE, Northeastern Brasil. Biotropica, Zurich, v. 29, n. 1, p. 57-68, 1997.

MAIA, G. N. Caatinga: árvores e arbustos e suas utilidades. São Paulo: D\&Z Computação Gráfica e Editora, 2004. 415 p.

MARCHIORETTO, M. S.; MAUHS, J.; BUDKE, J. C. Fenologia de espécies arbóreas zoocóricas em uma floresta psamófila no sul 
do Brasil. Acta Botanica Brasilica, São Paulo, v. 21, n. 1, p. 193 20, 2007.

MORELlATO, L. P. C. As estações do ano na floresta. In: MORELLATO, L. P. C.; LEITÃO-FILHO, H. F. (Ed.). Ecologia e preservação de uma floresta tropical urbana. Campinas: Editora da UNICAMP, 1995. p. 37-41.

MORELLATO, L. P. C.; RODRIGUES, R. R.; LEITÃO FILHO, H. F.; JOLY, C. A. Estudo fenológico comparativo de espécies arbóreas de floresta de altitude e floresta mesófila na Serra do Japi, Jundiaí, SP. Revista Brasileira de Botânica, São Paulo, v. 12, n. 1/2, p. 85-98, 1989.

MOURA, A. C. A. Primate group size and abundance in the caatinga dry forest. International Journal of Primatology, New York, v. 28, n. 6, p. 1279-1297, 2007.

NEVES, E. L.; FUNCH, L. S.; VIANA, B. F. Comportamento fenológico de três espécies de Jatropha (Euphorbiaceae) da Caatinga, semi-árido do Brasil. Revista Brasileira de Botânica, São Paulo, v. 33, n. 1, p. 155-166, 2010.

NEWSTROM, L. E.; FRANKIE, G. W.; BAKER, H. G. A new classification for plant phenology based on flowering patterns in lowland tropical rain forest at La Selva, Costa Rica. Biotropica, Zurich, v. 26, n. 2, p. 141-159, 1994.

PRAUSE, J.; ANGELONI, P. Fenología de especies forestales nativas: abscisión de hojas. Chaco: Universidad Nacional del Nordeste: Comunicaciones Científicas y Tecnológicas, 2000. Disponível em: <http://www1.unne.edu.ar/cyt/2000/5 agrarias/a pdf/a_058.pdf $>$.

RAMOS, A. C. S.; ZICKEL, C. S.; PIMENTEL, R. M. M. Fenologia da floração e frutificação de espécies do sub-bosque em um fragmento urbano de Floresta Atlântica do Nordeste - Brasil. Revista de Geografia, Recife, v. 23, p. 80-90, 2006.
RAMOS, F. N.; SANTOS F. A. M. Phenology of Psychotria tenuinervis (Rubiaceae) in Atlantic forest fragments: fragments and habitat scales. Canadian Journal of Botany, Ontario, v. 83, p. 1305-1316, 2005.

SANMARTIN-GAJARDO, I.; MORELLATO, L. P. C. Fenologia de Rubiaceae do sub-bosque em Floresta Atlântica no sudeste do Brasil. Revista Brasileira de Botânica, São Paulo, v. 26, p. 299 309, 2003.

SILBERBAUER-GOTTSBERGER, I. A hectare of Cerrado. II. Flowering and fruiting of thick-stemmed wood species. Phyton, Buenos Aires, v. 41, p. 129-158, 2001.

SILVA, C. S. P.; SANTOS, M. L. Comportamento fenológico no evento pós-queima e biologia reprodutiva de Spiranthera odoratissima A. St.-Hil. (Rutaceae). Biotemas, Florianópolis, v. 21, n. 1, p. 29-39, 2008.

SIQUEIRA FILHO, J. A.; SEIDO, C. L.; CAMPELO, M. J. A.; SANTO, F. S. E.; PEQUENO, I. D. Fenologia e síndromes de dispersão de espécies lenhosas em área prioritária para conservação da Caatinga - Afrânio, Pernambuco. In: ALBUQUERQUE, U. P.; MOURA, A. N.; ARAÚJO, E. L. (Ed.). Biodiversidade, potencial econômico e processos eco-fisiológicos em ecossistemas nordestinos. Vol. 2, Bauru: Canal 6, 2010. p. 463-484.

TALORA, D. C.; MORELLATO, L. P. C. Fenologia de espécies arbóreas em floresta de planície litorânea do sudeste do Brasil. Revista Brasileira de Botânica, São Paulo, v. 23, n. 1, p. 13-26, 2000.

TORRES, C.; GALETTO, L. Flowering phenology of cooccurring Asteraceae: a matter of climate, ecological interactions, plant attributes or of evolutionary relationships among species? Organisms Diversity \& Evolution, Vienna, v. 11, p. 9-19 2011.

ZAR, J. H. Biostatistical analysis. 3. ed. New Jersey: Prentice-Hall International Editions, 1999. 662 p. 